\title{
Degrees of separation
}

Stephen Hancocks OBE

Editor-in-Chief

In the midst of the hurly-burly of pre-Christmas activity you might be forgiven for having missed the following announcement from the General Dental Council (GDC): 'At a public meeting on 6 December 2007 the GDC agreed in principle to abolish its current system for adding dental professionals' additional qualifications to its registers.'

The 'agreement in principle' was something of a compromise due in no small part to the torrent of objections and comments received by the Council through the BDA and in particular members of its Representative Body. Had it not been for these interventions the abolition would almost certainly now be inked in. As it is, despite a hastily organised but as yet ill defined consultancy period, one suspects that the decision has already been made and 'in principle' there is nothing more anyone can do about it.

Two questions arise from these actions and both have fundamental importance for the role of the GDC and its relations with the dental profession.

\section{IS THERE MERIT IN THE PROPOSAL?}

The first question is whether the proposal has merit. The GDC gives the main reasons for change as its inability to quality assure qualifications, the possibility that inclusion misleads the public and the expense of having to do such a task properly. (It actually states 'disproportionately resource intensive to operate', which seems unnecessarily highbrow).

Given that the overwhelming majority of the public have no idea what a primary dental degree is, are they really likely to be misled by a further string of letters? For the most part patients select their dentist by word of mouth, followed at a considerable distance by advertisements and by directories. I think any of us would be hard pushed to identify even one of our patients who first arrived on the practice doorstep having checked the Dentists Register to discover whether or not we possessed a BDS or equivalent. Furthermore, patients stay with us out of trust, part of which is based on 'their' dentist's willingness to commit to updating knowledge and by further development, including additional study and qualifications.

No, what the GDC is saying in its role of 'protecting patients' is that the only thing the Council can guarantee about someone who calls themselves a dentist is that they have a primary qualification (or equivalent in the case of non-UK degree holders) which the GDC can verify as making them competent. Is that really protecting patients? Isn't that going back to the period 1921-2001 when the only things you had to do as a dentist were the acts of initial registration and annual retention payment? What happened to the great God of CPD? The GDC is unable, or unwilling, to quality assure that too, so is that also confusing to the public? Should we all stop taking additional qualifications, cease CPD and wait for the General Dental Police to catch up with us? Since this is the other part of the Council's tag line '...regulating the dental team', it is what the public is now being offered - we protect you by keeping a list of the names and addresses of people who have a primary dental degree and then discipline and prosecute them if you complain about them. Not much of a deal for the patient and lousy value for nearly £500 a year from 35,000 listed people, plus the cash from our newly ensnared DCP colleagues.

\section{ENGAGEMENT NOT DISTANCE}

Is it too cynical to suggest that an additional safeguard to patients is to engage with the profession that one is regulating to help improve knowledge, skills, safety, service and good practice? Perhaps, again, I am overestimating the extent to which the Council now sees its role in the light of government intervention. We are supposedly a 'self-regulated profession' and yet the GDC is no longer elected by us and clearly feels no need whatsoever to consult us, since the second of the fundamental questions raised by this matter is why there was to be no consultation period for this measure.

When this edict is in place, which it surely will be with the same inevitability of death and the need to pay taxes, our vanity may be hurt. We won't be able to point to a list of letters in the Dentists Register denoting further achievements in the form of additional qualifications to which we have chosen to commit. Yet this is unlikely to stop us undertaking such personal advancement since we will continue to want to improve our skills and knowledge thereby bringing greater patient care and professional personal satisfaction.

While the theory states that we are each connected to every other human being by a maximum of six degrees of separation, the GDC seems determined to separate itself from the dental profession by as many degrees as it can manage while still clinging to its credibility. Its website states the following with regard to the consultation: 'Further information about the consultation will be made available on this website [www.gdc-uk.org]. In the meantime please contact Moragh Loose, Quality Assurance Policy Manager, on 02078873819 or at mloose@gdc-uk.org with your views.'

Please do.

DOI: 10.1038/bdj.2008.22 